\title{
Exploring Barriers of the Health System to Rehabilitation Services for People with Disabilities in Iran: A Qualitative Study
}

\author{
Kianoush Abdi ${ }^{1}$, Mohammad Arab ${ }^{2}$, Arash Rashidian ${ }^{3}$, Mohammad Kamali ${ }^{4}$, Hamid Reza Khankeh ${ }^{5}$, Farideh \\ Khalajabadi Farahani ${ }^{6}$
}

${ }^{1}$ Ph.D. Student of Health Services Management, School of Public Health, Tehran University of Medical Sciences, Tehran, Iran

${ }^{2}$ Professor of Health Management, Department of Health Management and Economics, School of Public Health, Tehran University of Medical Sciences, Tehran, Iran

${ }^{3}$ Professor of Health Management and Economics, Department of Health Management and Economics, School of Public Health, Tehran University of Medical Sciences, Tehran, Iran

${ }^{4} \mathrm{Ph} . \mathrm{D}$. of Health Education, Associate Professor, Department of Rehabilitation Management, School of Rehabilitation Sciences, Iran University of Medical Sciences, Tehran, Iran

${ }^{5}$ Ph.D. of Nursing, Associate Professor, Department of Health in Emergency and Disaster and Nursing, University of Social Welfare and Rehabilitation Sciences, Tehran, Iran

${ }^{6}$ Ph.D. of Population Studies/Reproductive Health, Assistant Professor, Department of Population, Health and Family Planning, National Institute for Population Research, Tehran, Iran

\section{Type of article: Original}

\begin{abstract}
Introduction: The United Nations (UN) identified health as a basic human right, but, unfortunately, the evidence shows that people with disabilities (PWD) often have lower levels of health than the general population. This can be associated with problems in access to the services and programs. The aim of this study was to explore barriers of the health system to rehabilitation services for PWD in Iran.

Methods: This was a qualitative study conducted on 21 participants using semi-structured, in-depth interviews and content analysis from June 2014 to July 2015. Data analysis was performed by MAXQDA version 10.

Results: "Barriers" were the most prominent challenge of people with disabilities that needed access to rehabilitation services. These barriers were categorized into eight concepts of deficiency in the system that provides rehabilitation services, defect of education, deficiency in detecting and screening of people with disability, defect of stewardship in rehabilitation, ignoring socio-cultural factors, accessibility hardships, lack of identification, and financial hardships in rehabilitation.

Conclusions: An efficient rehabilitation plan requires a common understanding, considering the long-term complications involved in addressing the barriers. Understanding the barriers of the health system to rehabilitation services requires comprehensive management that first should be familiar with all of PWD, providers, policy makers, and other beneficiaries. It also is necessary for policy makers to consider rehabilitation services as a main part of the health plan; especially, they must change their oversight of rehabilitation services and programs. Thus, policy makers should have need comprehensive management and recommended further research.
\end{abstract}

Keywords: barriers; health System; rehabilitation; people with disability

\section{Corresponding author:}

Professor Dr. Mohammad Arab, Department of Health Management and Economics, School of Public Health, Tehran University of Medical Sciences, Enghelab Square, Tehran, Iran.

Tel: +98.2142933078, Fax:+98.2188989129, E-mail: arabmoha@tums.ac.ir

Received: Sepember 24, 2015, Accepted: November 01, 2015, Published: November 2015

iThenticate screening: October 14, 2015, English editing: November 03, 2015, Quality control: November 12, 2015

(C) 2015 The Authors. This is an open access article under the terms of the Creative Commons Attribution-NonCommercialNoDerivs License, which permits use and distribution in any medium, provided the original work is properly cited, the use is non-commercial and no modifications or adaptations are made. 


\section{Introduction}

The United Nations (UN) has identified health as a basic human right (1). Also, the World Health Organization (WHO) recognizes disability as a global public health issue, a human rights issue, and a development priority (2). Hence, achieving the full and equal human rights of disabled people is a social justice issue, not simply a resource issue (3). According to a report published by WHO, 15\% of the population of the world have disabilities (4). More than a billion people worldwide live with disabilities; 200 million of them have serious problems in their daily functioning (5). Persons with disabilities constitute the most marginalized group in the Asian and Pacific region (6). Approximately $15-20 \%$ of the world's poorest people are disabled (7). Van Doorslaer et al. estimated that absolute poverty in 11 Asian countries was $14 \%$ higher than conventional estimates. This does not take into account of outof-pocket payments for health care (8). The Convention on the Rights of Persons with Disabilities (CRPD) is entitled to consider the enjoyment right of health of PWD. Therefore, Article 25 of the Convention requires States to "recognize the right of persons with disabilities to the enjoyment of the highest attainable level of health, regardless of disability." Article 20 (Access) and Article 26 (Rehabilitation) address that Member States shall ensure that persons with disabilities have access to health services, including rehabilitation based on gender (9). Global survey experts on disability issues, including health policy and clinical ratings, stated that PWD in access to appropriate levels of health services, which are obstacles, and show how these barriers can be overcome (10). The number of PWD in the world is increasing due to different factors, such as population growth, increasing chronic disease, aging, and medical advances that can sustain the quality of life of such disabled. These issues create unreasonable demands for health services and rehabilitation, especially in low-income countries (11). Many disabled people who are in the same level as other people are in need of health promotion programs (12). But, unfortunately, the evidence shows that PWD often have lower levels of health than the general population (13-15). Although undesirable health of PWD is not necessarily a direct result of their disability, it can be associated with problems of access to the services and programs (16). But based on international evidence, disabled people have many unmet health and rehabilitation needs and face barriers to access to health services $(10,17,18)$. Govender stated the major structural barriers to health are usually legislative, policy, or regulative measures that hinder the practice of good health (19). Also, Johnson et al. mentioned health services issues as one of the main barriers for people with advanced cancer (20). Therefore, health promotion, prevention of disorders, preventing and reducing disability and the individual correction function, and reducing the handicap phenomenon are the major goals of rehabilitation (21). If the programs are approached in a holistic manner, rather than as an isolated divided task, it will be possible to prevent disunity, overlap, and wasting of resources (22). Thus, governments should pave the way for disability rights and provide the support that is necessary for them (23). The literature review on rehabilitation services showed that the health capacities of PWD are often overlooked (13-15). As a result, they are often isolated from the country`s health promotion activities. In reality, the health of PWD depends on a wide range of factors, and the health sector alone cannot bear the entire load. Therefore, this study was conducted with the objective of identifying the barriers of the health system to the rehabilitation of PWD in Iran.

\section{Material and Methods}

\subsection{Study design}

A qualitative approach using content analysis was employed in this study. In this method, the required data were gathered directly from the participants, without any pervious hypothesis. Produced knowledge was obtained on unique perspectives of participants. Codes and categories were derived by an inductive process and concepts were ordered in terms of their related properties and dimensions (24).

\subsection{Setting and participants}

The participants were selected in Tehran (Capital of Iran) using a purposeful sampling method with a maximum variation based on first-hand experience, expertise, and also their willingness to participate in research. Data collection was continued until we reached a point of data saturation. The participants included seven providers of rehabilitation services, four PWD, four families with PWD, two people from non-government organizations (NGO), and four policy makers who had scientific expertise in the rehabilitation system of Iran.

\subsection{Data Collection}

Semi-structured, in-depth interviews were utilized to gather data. Data gathering was conducted by the main researcher through interviews from June 2014 to July 2015. Before the interviews, by introducing the aim of the study, the researcher obtained the informed and written consent from participants. The interviews lasted for 45 to 90 minutes and were tape recorded and transcribed verbatim. All quotations stated in this paper were translated from Persian into English by the main researcher. One of authors, who is familiar with English, checked the accuracy of 
the translations. Each interview started with a broad question about "Participants perception and experience of barriers of health system to rehabilitation services." Probing was conducted according to reflection of each participant on rehabilitation services, such as perception of the rehabilitation, services and their needs, and the barriers to providing rehabilitation services in Iran.

\subsection{Data Analysis}

Qualitative content analysis was used to analyze the data. The study process was continued, and concurrent analyses were undertaken. First, recorded interviews were transcribed verbatim. Second, before coding, the transcribed text was read several times for familiarization. Codes and categories were extracted by an inductive process with an open coding through reading of the text then assigned related codes to them. Then, the categories were obtained through systematic comparison. Peer check and systematic comparison were used to reach a consensus in coding. Actually, data analysis was performed concurrently with data gathering. After completion of coding and assuring its precision, various concepts were identified. Data analysis was performed by MAXQDA version 10.

\subsection{Trustworthiness of data}

In this study, we used the strategies suggested by Lincoln and Cuba, and there were four criteria, i.e., creditability, dependency, conformability, and transferability, that were essential for trustworthiness (25). For the creditability of the data, the researcher prolonged the engagement with the data and participants for 11 months, while frequently conducting interviews (26). In addition, dependency was assessed by peer check and member check strategies (27). Peer check was conducted by the other research team about the appearance of the data and member check was performed by reflecting the abstract of the interview to the participant in the interview process for dependency of data. The background and interest of the researcher on the matter and preservation of documents of research were used to enhance the conformability of the data (25). The research team and another faculty member of qualitative research reviewed the texts of interviews, codes, and the extracted categories. The researchers were able to collect a broad variety of different comments and interpretations by utilization sampling with a maximum variation.

\subsection{Ethical considerations}

Written informed consent was obtained from all participants after clarifying the purpose and process of the research orally and in script. This study was conducted to fulfill the requirements of the Ph.D. degree of the main researcher, and it was approved by the Ethics Committee of Tehran University of Medical Sciences (TUMS). All participants' information was kept confidential, and all participants had the right to withdraw from the research at any time.

\section{Results}

\subsection{Demographic characteristics}

The results of this study from the experiences and perceptions of 21 people who participated in the study, i.e., 16 males and 5 females, including 4 PWD, 7 providers from the disciplines of rehabilitation, 4 family members with PWD, 2 people from NGOs, and 4 people who were policy makers that had scientific expertise in the rehabilitation system of Iran (Table 1). The study provided a new perspective on the important problems of the rehabilitation services process. Furthermore, the findings identified eight main categories of barriers in rehabilitation for access to health services. These main categories and their subcategories are mentioned (Table 2).

\subsection{Deficiency in system of rehabilitation services provision}

The findings indicated that the system of providing rehabilitation services was a category that included various sectors with different stakeholders, e.g., key informants, providers, PWD and their families, and NGOs, therefore providing desirable services requires attending to all of the actors in the rehabilitation system, and their consequences depend on several factors. Experiences of the participants indicated that system of providing rehabilitation services has significant obstacles in the provision of rehabilitation services. One of the participants explained the issue as: "... Unfortunately, the missing link of the rehabilitation profession in our country is team working. I think having a well-organized team working will make sensible achievements ..." (Provider). Another participant noted the issue as: "...I believe lack of "rehabilitation department" within the health system and specifically speaking, the Ministry of Health and Medical Education will put the rehabilitation management system in serious challenge. Within the Ministry you find various offices and departments but you may find nothing on rehabilitation. At the time I do not want to mention any specific deputy. Until we have Department of rehabilitation with independent identity within Ministry of Health we will face many challenges in managing of rehabilitation." (Policy maker). A third participant explained this issue as: "No inspection system on how well the service is being 
delivered has been defined. A monitoring system the best of which might be the concomitant control method which is simultaneous control of service quality is essential. We need a control system for rehabilitation services delivery like many other countries or what we have within our "Medical Council". Individuals will lose their connection with the supervision and regulatory body after being registered. I think the problem is that there is no supervision system for encouragement or punishment." (Provider).

\subsection{Defect of education in rehabilitation}

The findings indicated that there were obstacles in the process of education and weaknesses in the comprehensive education at universities with the responsibility of providing training in the rehabilitation discipline. The participants believed that it is necessary to empower the providers in varying dimensions of knowledge, attitude, and skill in the system of education with appropriate measures before they graduate. A provider mentioned:“... honestly, I find only 30 percent of the information learned by occupational therapists to be practical and useful in their practice and not any more than takes ..." (Provider). Another participant explained the situation as: "In our own university, what is being presented for students to be graduated after four years of study? What is their attitude to the family bringing their children to the clinic to receive rehabilitation service? How are students educated on these aspects? (Family of PWD). Another provider stated: “... that shows the scientific surround of providers is questionable. The next point is that these students have problems in the areas of assessment and diagnosis of patients. It seems, their clinical courses must be expanded and be majorly focused on clinical issues." (Provider).

\subsection{Deficiency in detecting and screening of PWD}

The deficiency in detecting was one of the problems for clients in the area of rehabilitation in our country. There is a confusing process for clients that want to detect whether their disabilities are in the areas of physical, mental, cognitive, social, or emotional, and that takes a very long process. Generally, the physicians will have different referees, because physicians are not well aware of the areas in which rehabilitation can be provided. The participants emphasized the importance and priority of detecting of PWD to access to rehabilitation services after disability. One of the participants stated: “...We have no rehabilitation screening system in our country, for example there is an optometry screening system for 6 years old children in our kindergartens and elementary school. I think it would be beneficial having the same rehabilitation screening system at school entry levels." The most important problem is that these children are not easily distinguished from the healthy children and those with other impairments." (Provider). Another participant argued that they have special problems with the medical system: "The next problem is a medical system has not very familiar with domains of services rehabilitation system that it can provide in our country. In generally refers are incomplete and wrong." (Provider).

\subsection{Defect of stewardship in rehabilitation}

Stewardship was an important obstacle in the system of rehabilitation, but the absence of this subject as a central coordinator in our country and involvement of multiple organizations in the provision of rehabilitation services have created fundamental problems. One of the participants said: "Many of the policy makers are not familiar with or have not been engaged in this field. I think there is no clear law in the parliament for the disability and handicap fields so that certain organizations are responsible for..." (Provider). In addition, another participant described the issue: “... Ministry of Health, Welfare organization, Red Crescent, War Veterans Affairs foundation, nongovernmental organs are all engaged in this field and their activities are sometimes parallel. They are all working very hard and the government and the health system are spending costs but no clear stewardship exists" (Provider). The third participant stated the issue: "... A central coordinator is required to organize the dispersion of rehabilitation field activities and play the role of a focal point. This focal point is missing ..." (Policy maker).

\subsection{Ignoring of sociocultural factors}

The findings showed that sociocultural factors have a prominent role in the provision of rehabilitation services to individuals with disability. Inattention to them will result in family and social consequences. A participant said: “...Some physical disabilities will lead to deformities so that the family becomes reluctant that the disables member appears in public. This is while the handicapped has the right to go out. While working for the welfare organization, I knew families who did not report the presence of their handicapped member during the census." (Family of PWD). Another participant explained: “...Another problem is with the team work approach towards rehabilitation. This socio-cultural problem may take at least two decades to be solved and the consensus be reached that rehabilitation is a multidisciplinary field. The specialists have a top to bottom approach towards rehabilitation team members like the approach of Otolaryngologist towards speech therapist and behave in an arbitrary manner and this is a reality." (Provider). 
Table 1. Sectors Represented by Study Participants

\begin{tabular}{|c|c|c|c|c|c|}
\hline \multirow[t]{2}{*}{ Sector } & \multirow[t]{2}{*}{ Type of participant } & \multicolumn{2}{|l|}{ Sex } & \multirow{2}{*}{$\begin{array}{l}\text { Experience } \\
\text { (year) }\end{array}$} & \multirow[t]{2}{*}{$\mathrm{n}$} \\
\hline & & Male & Female & & \\
\hline $\begin{array}{l}\text { People with } \\
\text { disability }\end{array}$ & $\begin{array}{l}\text { Physical disability } \\
\text { Physical disability } \\
\text { Physical disability } \\
\text { Physical disability }\end{array}$ & $\begin{array}{l}* \\
*\end{array}$ & * & $\begin{array}{l}10 \\
20 \\
27 \\
19\end{array}$ & 4 \\
\hline Provider & $\begin{array}{l}\text { Physiotherapist } \\
\text { Occupational therapist } \\
\text { Orthosist } \\
\text { Speech therapist } \\
\text { Speech therapist } \\
\text { Occupational therapist } \\
\text { Speech therapist }\end{array}$ & $\begin{array}{l}* \\
* \\
* \\
* \\
*\end{array}$ & $\begin{array}{l}* \\
*\end{array}$ & $\begin{array}{l}20 \\
17 \\
15 \\
10 \\
25 \\
15 \\
26\end{array}$ & 7 \\
\hline Policy maker & $\begin{array}{l}\text { Deputy of Welfare Organization } \\
\text { Director General of Welfare } \\
\text { Organization } \\
\text { Director General of Red Crescent } \\
\text { Director General of Welfare } \\
\text { Organization }\end{array}$ & $\begin{array}{l}* \\
* \\
* \\
*\end{array}$ & & $\begin{array}{l}30 \\
20 \\
18 \\
19\end{array}$ & 4 \\
\hline NGO & $\begin{array}{l}\text { Director of NGO } \\
\text { Director of } \mathrm{NGO}\end{array}$ & * & & $\begin{array}{l}15 \\
20 \\
\end{array}$ & 2 \\
\hline $\begin{array}{l}\text { Family of People } \\
\text { with disability }\end{array}$ & $\begin{array}{l}\text { Physical Disability } \\
\text { Mental retardation } \\
\text { Down syndrome } \\
\text { Cerebral palsy }\end{array}$ & $\begin{array}{l}* \\
* \\
*\end{array}$ & $*$ & $\begin{array}{l}9 \\
20 \\
18 \\
11\end{array}$ & 4 \\
\hline Total & & 16 & 5 & & 21 \\
\hline
\end{tabular}

Table 2. Overview of identified barriers and their subcategories (Categories and subcategories)

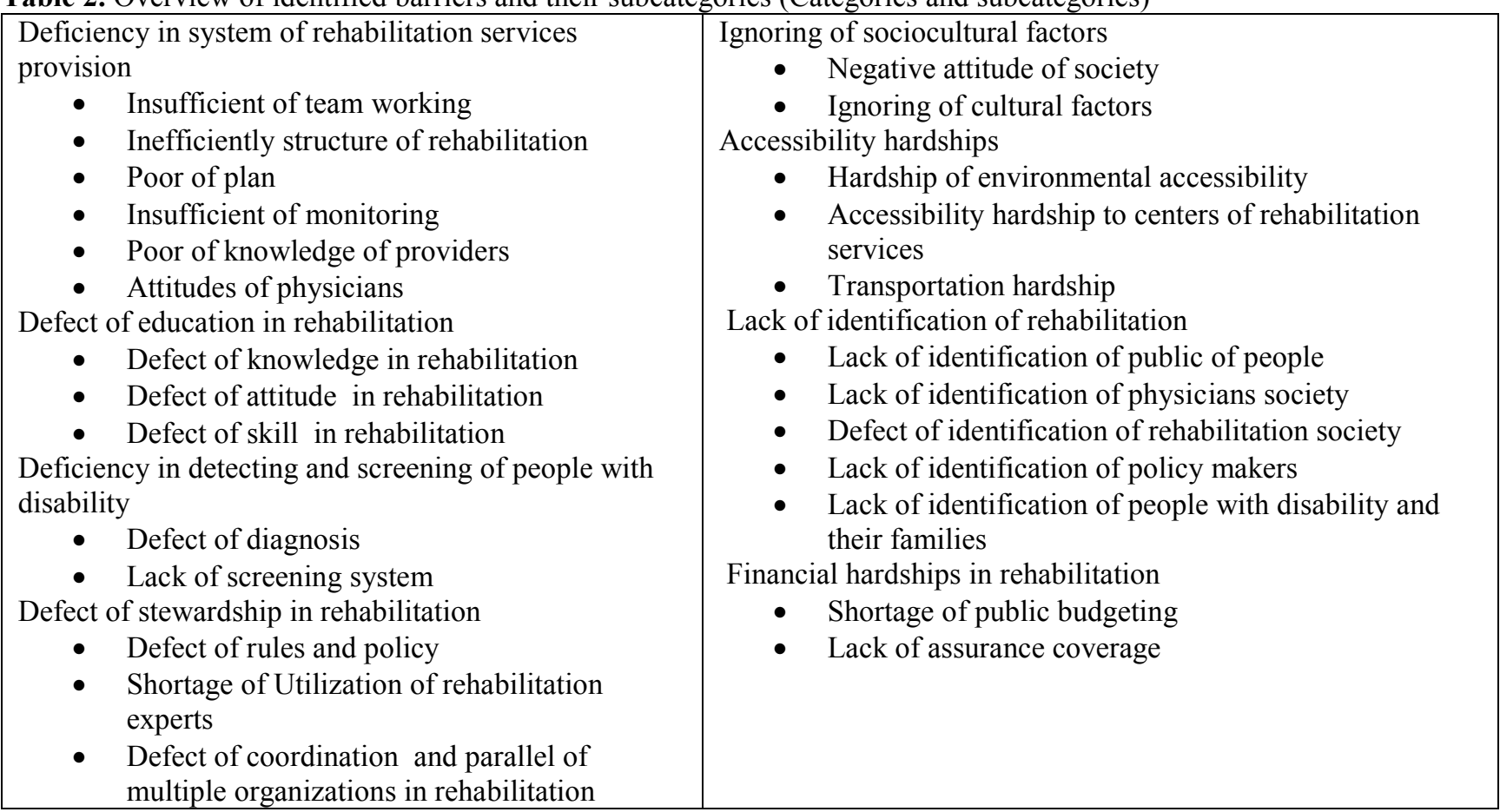




\subsection{Accessibility hardships}

Most of the participants have challenges with accessibility as one of the consequences of disability. The findings showed that the accessibility challenge of PWD exists at all levels of environmental, transportation, and access to rehabilitation services. In many cases, accessibility hardships led to such intensification of the disability that it became a handicap. One of the participants described it as: "Accessibility to centers is a great problem for PWD. For example there are no centers in small towns and deprived areas. Accessibility has different aspects; not only physical but also financial accessibility is a concern since rehabilitation service is expensive. One rehabilitation center told us when subsidies are paid, our cancellation statistics will decrease. However, this is the biggest barrier." (Policy maker). Another participant mentioned the issue: "transportation of PWD, when they want to go to work, the university, high school, the doctor, the park or home one of their kinfolk at least once a month." (PWD).

\subsection{Lack of identification of rehabilitation}

The findings indicated that "lack of identification of rehabilitation" was one of the main concerns of people who have a disability, a subject that was latented in most of the research codes. Participants reported that they experienced a significant lack of identification with rehabilitation services. One of the participants explained this concept as follows: “... Rehabilitation is not well known even for the health system. The health system in general including the health ministry, physicians practicing in their offices, students of medical sciences and even members of the rehabilitation team themselves are not familiar with other rehabilitation fields. Therefore our problem originates from the fact that the rehabilitation disciplines are not known." (provider). Another participant said the issue: "Unfortunately, rehabilitation in our country is very obsolete. I got familiar with rehabilitation after I felt the need for it. In other word until you do not feel the need, there will be no attention towards rehabilitation and that is just when you will feel its effect..." (Family PWD). A third participant explained it as: "Many people do not know what rehabilitation is. Because as a reality specialists linked with rehabilitation team members, such as an orthopedist or neurosurgeon linked with physiotherapists or an Otolaryngologist linked with a speech therapist or a pediatrician linked with an occupational therapist, all wish to take best care of their patients." (Provider).

\subsection{Financial hardships in rehabilitation}

Due to financial problems for transporting, rehabilitation services, and other current expenditures, most of the PWD need significant assistance, and disabled Iranian people cannot receive desirable services. Participants mentioned that they do not the ability to provide these expenditures for access to rehabilitation services. One of the participants explained it as: "It is of no use when they approve a seemingly good conditioned law or regulation. I mean sometimes there are numerous articles for a law the last of which makes the prerequisite for all others that the financial sources are provided. That is when organizations do not perform the regulation with the excuse of the financial resources not being provided." (N.G.O). Another participant described it as: "We have basic problems in the rehabilitation insurance and policy makers in the field of rehabilitation and social welfare should consider that, we might have for example a million cold cases a year. The insurance covers their costs. But how many spinal cord injury and cerebral palsy cases do we have? (Provider).

\section{Discussion}

The purpose of this study was to identify the barriers of the health system to rehabilitation services in Iran. This study is one of the studies on rehabilitation that has addressed these barriers from the viewpoints of all of the stakeholders of rehabilitation, such as policy makers, providers, NGO, PWD, and families. Based on the literature, which was reviewed by the main researcher, in Iran, no similar study has been conducted in which the viewpoints of all the stakeholders who were involved in rehabilitation services were considered. But, other studies have addressed some of the aspects of the current study, such as financing, accessibility, and attitude, and little attention has been paid to other barriers, including stewardship, education, screening, and identification in rehabilitation. In general, there is no evidence, based on the definition of barriers of rehabilitation services in the literature, but, considering the importance of the context in rehabilitation, specific studies in this area are necessary.

A financial hardship in rehabilitation was one of the important challenges that mentioned in this study that also was emphasized in previous studies (28-32). All of the participants are faced with this challenge that can disrupt continuing rehabilitation in the long term, resulting in a disability becoming a handicap. Lack of insurance coverage and out-of-pocket payments were main concerns in many numbers of rehabilitation services to PWD and their families because rehabilitation services are provided in long term and based on evidence PWD are the poorest group of population. The negative attitude was another barrier in the current study and in previous studies $(5,28,33)$. More than an intensification of disability can be due to the negative attitude about the disability of society, provider, 
family, and themselves PWD. And another aspect of rehabilitation services discussed here was the hardships of accessibility that were confirmed by past studies (29-31, 34, 35). Most of the participants have challenges with accessibility difficulties as one of the consequences of disability that appears as a consequence of personal, family, and social situations. The lack of detecting and screening one of the barriers was explored in the current study. This barrier was reported by Merton et al. in 2015 in their paper, "Barriers to cancer screening for PWD" (36). Overlooking this obstacle can impose heavy costs on the health system. Defect of education in rehabilitation was another hindrance for provider PWD and their families to health services, as confirmed by previous studies $(16,37)$. Hence, greater attention is needed on accessing and improving of rehabilitation services. Based on the literature that was reviewed by the researcher, the defect of stewardship has been found to be a structural barrier in previous studies. This subject can be due to context of rehabilitation services in Iran and distribution of providing of services by several organizations, such as the Ministry of Health, the Welfare Organization, and the Red Crescent. Meanwhile, stewardship is integrated in most countries.

In 2012, Kleinitz et al. found barriers including finances, quality of care, user knowledge, sociocultural negative beliefs and attitudes, and physical access to health care for people with disabilities (5), their study overlooked other involvements in the rehabilitation process. They did not identify barriers, such defect of stewardship, lack of identification and screening of PWD, defect of education, and defect of "system of rehabilitation services provision." Another study conducted by Nguon found the three most significant barriers to disability-inclusive local governance and community development were discrimination and negative attitudes; limited understanding of the rights and capacities of persons with disabilities, not only within the family, community, and local authorities, but also within themselves; and limited financial, technical, and human resources to promote inclusion and improve access to appropriate services (28). The findings of Fisher showed that various factors, namely poor information, shortage of services, and affordability across China, the local context, such as resources and social policy implementation, affect the degree to which families obtain the support they need (38). While their study was conducted in order to evaluate access to health care by children with disabilities and their families, it identified the structural barriers to access health care from the viewpoint all of the stakeholders in providing rehabilitation services. Jacobs et al. presented an overview of the various dimensions of barriers to access to health care in lessdeveloped countries, availability, affordability, geographical and acceptability access to overcoming these barriers outline existing interventions were designed (31). But the current study only identified barriers irrespective of recommendations for removing and promotion of rehabilitation services. Ensor and Cooper identified barriers in two categories, i.e., demand side and supply side.

1) Explored barriers on the demand side included:

- Information on health care choices/providers

- Education

- Indirect consumer costs

- Household preferences

- Community and cultural preferences, attitudes and norms

2) Barriers that were mentioned on the supply side included (39):

- Input prices and input availability

- Technology

- Management/staff efficiency

While this study did not classify the barriers but mentioned education, finance, and sociocultural factors that they had addressed. Neri and Kroll understood five consequences of access barriers to health care that included social, psychological, physical, economic, and independence issues (40). But these findings related to barriers of rehabilitation process that needs to address to their consequences each of barriers in other studies. Kronfol conducted a review study in Arab countries that showed issues related to morbidity, transportation, patient-provider relationship, cost, stigma, and organizational barriers that often impede access and compliance with the care provided or recommended (35). The findings of this study will help in reaching an understanding of the experiences all of the participants concerning their access to health care and the confirmed barriers, such as cost and transportation. Marlow et al. found financial and administrative barriers to care; structural facilitators to care; and the influence of clinicians' professional demeanor on health care access (32). Their study considered the structural facilitators, and another point was addressed to the behaviors of providers of access to health care, unlike this study, which ignored them. Maart mentioned the main problems with accessing services included inadequate finances and 
transportation problems (29). While in this study, in addition, these problems were stated to other barriers, such as stewardship, education, sociocultural issues, and the provision of services.

The complexity and wide variations in the process of rehabilitation services has caused people with a disability to face several challenges in accessing to health services. However, the data were gathered from participants using purposeful sampling, as dedicated by qualitative methods. Therefore, the findings cannot be generalized to any other country. This research displays a starting point for explaining and exploring the barriers of rehabilitation services for access to health care after disability. Further study is needed. There is a need for further assessment of the rehabilitation process after disability and using Grounded Theory approach will help policy makers consider rehabilitation as an effectiveness factor in the health care system.

The main strength of this study was that the main researcher through facing many challenges that were experienced or observed closely in the system of rehabilitation services in process of research, while the findings of this study provide a basis for understanding the challenges to the provision of rehabilitation services. The limitations must be identified. First the results did not explore a variety of types of participants, namely PWD, providers, key informants, and other participants. Secondly, the current research did not have a comparable person with disability with people without disability. In spite of these limitations, the findings have valuable implications for key informants in policy making and planning for PWD to rehabilitation services by the health system..

\section{Conclusions}

Barriers were explored, including eight concepts; deficiency of system of rehabilitation services provision, defect of education, difficult of detecting and screening of people with disability, defect of stewardship, ignoring sociocultural factors, accessibility hardships, lack of identification, and financial hardships. Understanding barriers of rehabilitation services for access to health needs a comprehensive management that first should be familiar with all of PWD, providers, policy makers, and other beneficiaries. It is also necessary that policy makers consider barriers of health system to rehabilitation services as a main part of the health plan; especially, they must change their oversight to rehabilitation services and programs. All stakeholders are recommended to change of viewpoints about rehabilitation needed to promote a culture of continuous, prolonged, and comprehensive process in varied sectors of the country. Further investigations are recommended to explore the real process of rehabilitation in the Iranian health system.

\section{Acknowledgments:}

This paper was extracted from the main author's doctoral thesis; therefore, we thank all involved experts in the process of the research, including supervisors and advisors. This study received no grant from any institution in the public or non-government sectors.

\section{Conflict of Interest:}

There is no conflict of interest to be declared.

Authors' contributions:

All authors contributed to this project and article equally. All authors read and approved the final manuscript.

\section{References}

1) Gulliford M, Morgan M.(eds). Access to health care:New York. Routledge; 2013.chapter 1.p:2

2) World Health Organization. global disability action plan 2014-2021: better health for all People with diability. World Health Organization. Available from: http://www.who.int/disabilities/actionplan/en/.April 2014. Accessed August 11, 2015.

3) Pillai R, Rankin J, Bennett J, Hetherington D, Stone L, Withers K. DISABILITY 2020: Opportunities for the full and equal citizenship of disabled people in Britain in 2020. IPPR Trading for the Disability Rights Commission, London; 2007.

4) World Health Organization. World report on disability: World Health Organization; Available from: http://www.who.int/disabilities/world_report/2011/report/en/. 2011. Accessed August 82015

5) Kleinitz P, Walji F, Vichetra K, Nimul O, Mannava P. Barriers to and Facilitators of Health Services for People with diabilities in Cambodia. 2012.

6) Takamine Y. Disability issues in East Asia: Review and ways forward: World Bank; 2004. 
7) Elwan A. Poverty and disability: A survey of the literature: Social Protection Advisory Service; World Bank; 1999.

8) Van Doorslaer E, O'Donnell O, Rannan-Eliya RP, Somanathan A, Adhikari SR, Garg CC, et al. Effect of payments for health care on poverty estimates in 11 countries in Asia: an analysis of household survey data. Lancet. 2006; 368(9544): 1357-64. doi:10.1016/S0140-6736(06)69560-3, PMID: 17046468

9) Enable U. Convention on the Rights of Persons with Disabilities. Available from: http://www.un.org/disabilities/convention/conventionfull.shtml.2006.

10) Tomlinson M, Swartz L, Officer A, Chan KY, Rudan I, Saxena S. Research priorities for health of People with diabilities: an expert opinion exercise. Lancet. 2009; 374(9704): 1857-62. doi:10.1016/S01406736(09)61910-3, PMID: 19944866

11) World Health Organization. Disability and Rehabilitation WHO Action Plan 2006-2011. Available from: http://www.who.int/disabilities/publications/action_plan/en/. 2005.

12) Harrison $T$. Health promotion for persons with disabilities: what does the literature reveal? Fam Community Health. 2006; 29(1): 12S-19S, PMID: 16344632

13) Kroll T, Jones GC, Kehn M, Neri MT. Barriers and strategies affecting the utilisation of primary preventive services for people with physical disabilities: a qualitative inquiry. Health Soc Care Community. 2006; 14(4): 284-93. doi: 10.1111/j.1365-2524.2006.00613.x, PMID: 16787479

14) Becker H. Measuring health among PWD. Fam Community Health. 2006; 29(1): 70S-77S, PMID: 16344639.

15) Krause JS, Coker J, Charlifue S, Whiteneck GG. Health behaviors among American Indians with spinal cord injury: comparison with data from the 1996 Behavioral Risk Factor Surveillance System. Arch Phys Med Rehabil. 1999; 80(11): 1435-40. doi: 10.1016/S0003-9993(99)90255-1, PMID: 10569438.

16) Rimmer JH, Rowland JL. Health promotion for People with diabilities: Implications for empowering the person and promoting disability-friendly environments. Am J Lifestyle Med. 2008; 2(5): 409-20. doi: 10.1177/1559827608317397.

17) Yen CF, Chen SF, Lin LP, Hsu SW, Chang MJ, Wu CL, et al. The acceptability of human papillomavirus (HPV) vaccination among women with physical disabilities. Res Dev Disabil. 2011; 32(5): $2020-6$. doi:10.1016/j.ridd.2011.04.006, PMID: 21571498.

18) Hwang K, Johnston M, Tulsky D, Wood K, Dyson-Hudson T, Komaroff E. Access and coordination of health care service for People with diabilities. Journal of Disability Policy Studies. 2009; 20(1): 28-34. doi: $10.1177 / 1044207308315564$.

19) Govender R. The barriers and challenges to health promotion in Africa: review article. SA Fame Pract. 2005; 47(10): 39-42.

20) Johnson C, Paul C, Girgis A, Adams J, Currow DC. Australian general practitioners' and oncology specialists' perceptions of barriers and facilitators of access to specialist palliative care services. J Palliat Med. 2011; 14(4): 429-35. doi:10.1089/jpm.2010.0259, PMID: 21385085.

21) Mohammadi F. Theoretical foundations of nursing rehabilitation. Tehran, Iran: University of Social Welfare and Rehabilitation; 2012: 19.

22) Kamali M. An Overview of the Situation of the Disabled in Iran. Advancing the Rights of Persons with Disabilities: A US-Iran Dialogue on Law, Policy, and Advocacy. 2011:15.

23) Noudehi A. Foundations for rehabilitation. 2th ed. Tehran, Iran: University of Social Welfare and Rehabilitation. 2006: 5

24) Corbin J, Strauss A. Basics of qualitative research: Techniques and procedures for developing grounded theory: Sage publications; 2014.

25) Guba EG. Criteria for assessing the trustworthiness of naturalistic inquiries. ECTJ. 1981; 29(2): $75-91$.

26) Beck CT. Qualitative research: the evaluation of its credibility, fittingness, and auditability. West J Nurs Res. 1993 (15): 263-6, PMID: 8470379

27) Lincoln YS. Emerging criteria for quality in qualitative and interpretive research. Qual Inq.1995; 1(3): 27589. doi: 10.1177/107780049500100301.

28) Nguon SK. Situation analysis for disability-inclusive governance and community development in Cambodia. 2014: 28-9.

29) Maart S, Jelsma J. Disability and access to health care-a community based descriptive study. Disabil Rehabil. 2014; 36(18): 1489-93. doi:10.3109/09638288.2013.807883, PMID: 23829353 
30) Whiteneck GG, Harrison-Felix CL, Mellick DC, Brooks CA, Charlifue SB, Gerhart KA. Quantifying environmental factors: A measure of physical, attitudinal, service, productivity, and policy barriers. Arch Phys Med Rehabil. 2004; 85(8): 1324-35. doi:10.1016/j.apmr.2003.09.027, PMID: 15295760

31) Jacobs B, Ir P, Bigdeli M, Annear PL, Van Damme W. Addressing access barriers to health services: an analytical framework for selecting appropriate interventions in low-income Asian countries. Health Policy Plan. 2012; 27(4): 288-300. doi: 10.1093/heapol/czr038, PMID: 21565939.

32) Marlow E, White MC, Chesla CA. Barriers and facilitators: parolees' perceptions of community health care. J Correct Health Care. 2010; 16(1): 17-26. doi: 10.1177/1078345809348201, PMID: 19861321

33) Kroll T, Neri M. Experiences with care co-ordination among people with cerebral palsy, multiple sclerosis, or spinal cord injury. Disabil Rehabil. 2003; 25(19): 1106-14. doi: 10.1080/0963828031000152002, PMID: 12944150

34) Van Rooy G, Amadhila EM, Mufune P, Swartz L, Mannan H, MacLachlan M. Perceived barriers to accessing health services among PWD in rural northern Namibia. Disabil Soc. 2012; 27(6): 761-75. doi: 10.1080/09687599.2012.686877.

35) Kronfol N. Health services to groups with special needs in the Arab world: a review. 2012; 18 (12), 1247 53. Available from: http://www.who.int/iris/handle/10665/118477, PMID: 23301400.

36) Merten JW, Pomeranz JL, King JL, Moorhouse M, Wynn RD. Barriers to cancer screening for PWD: A literature review. Disabil Health J. 2015; 8(1): 9-16. doi: 10.1016/j.dhjo.2014.06.004.

37) Peterson-Besse JJ, Walsh ES, Horner-Johnson W, Goode TD, Wheeler B. Barriers to health care among people with disabilities who are members of underserved racial/ethnic groups: a scoping review of the literature. Med Care. 2014; 52(10): S51-63. doi: 10.1097/MLR.0000000000000195, PMID: 25215920

38) Fisher KR, Shang X. Access to health and therapy services for families of children with disabilities in China. Disabil Rehabil. 2013;35(25):2157-63. doi: 10.3109/09638288.2013.770566, PMID: 23614374

39) Ensor T, Cooper S. Overcoming barriers to health service access: influencing the demand side. Health policy plan. 2004; 19(2): 69-79. doi: 10.1093/heapol/czh009, PMID: 14982885.

40) Neri MT, Kroll T. Understanding the consequences of access barriers to health care: experiences of adults with disabilities. Disabil Rehabil. 2003;25(2):85-96. doi: 10.1080/0963828021000007941, PMID: 12554383 . 